\title{
Effectiveness of holmium laser therapy with 7-Fr ureterorenoscopy in preschool children
}

Mehmet Özgür YÜCEL ${ }^{1}$, Ali çiFT' ${ }^{1}$, Can BENLiOĞLU1

${ }^{1}$ Department of Urology, Faculty of Medicine, Adıyaman University, Adıyaman, Turkey.

\section{SUMMARY}

This study aimed to evaluate the success of semi-rigid (7-Fr) ureterorenoscope in treating ureteral stones in preschool children (aged $0-6$ years).

A total of 36 patients who underwent endoscopic ureteral stone treatment in the clinic were retrospectively evaluated between January 2012 and February 2018. During the procedure, a 7-Fr semi-rigid ureterorenoscope holmium: YA G laser as lithotripter were used. The stone-free rates of the patients were evaluated visually during fragmentation and 1 month later using urinary ultrasonography.

The mean age of the patients was 37.5 months, $55.6 \%$ were male, and $44.4 \%$ were female. Stone localization was $58.3 \%$ in the distal ureter, $16.7 \%$ in the middle ureter, and $25 \%$ in the proximal ureter. After the first ureterorenoscopy procedure, the stone-free rate was $58.3 \%$. During the first ureterorenoscopy procedure, $38.9 \%$ patients were admitted with a double $J$ stent, which could not reach intraoperative stones. After 1 month, second-session ureterorenoscopy was performed. During the first ureterorenoscopy procedure, ureteral perforation developed in $2.8 \%$ of the patients. Ureterolithotomy was performed with open surgery. After the first and second ureterorenoscopy procedures, the stone-free rate was $97.2 \%$. Slight bleeding in two patients and high fever $\left(>38.5^{\circ} \mathrm{C}\right)$ in four patients was observed in the early postoperative period. The mean hospital stay was 2.3 days.

Endoscopic ureteral stone treatment with 7-Fr ureterorenoscopy can be safely performed with high success and low complication rates even in very young children.

Key words: Children, holmium: YAG laser, ureteral stones, ureterorenoscopy

\section{INTRODUCTION}

Urinary system stone disease (USSD) in children differs from that in adults in terms of etiology, incidence, and course of the disease. It is relatively rare with a general incidence rate of 2\%-3\% (1,2). USSD in children usually occurs due to an underlying disease or disorder such as anatomic and metabolic anomalies or recurrent urinary tract infections (3). The probability of the recurrence of USSD in children is 15\%, while this rate was reported as $37.5 \%$ in children with metabolic anomalies (4). Therefore, considering the possibility of recurrence in older ages, it is highly important to apply minimally invasive practices for pediatric patients.

Treatment of ureteral stones in children involves different options such as symptomatic treatment, expulsive treatment, extracorporeal shock wave lithotripsy (ESWL), and endoscopic, laparoscopic, and open surgery. The selection of treatment is affected by technological capacity, treatment cost, experience of the surgeon, and patient preference, In addition to factors such as localization, number, and size of the stones, kidney functions, and degree of hydronephrosis.

The disadvantages of ESWL are the requirement of repeated sessions in children, repeated use of general anesthesia, and exposure to radiation (4). Endoscopic methods have become more effective and safer with improvements in instrumentation 
and technology (5). The main technical developments include miniaturization of endoscopes, developments in imaging techniques, and reductions in the dimensions of equipment (6). Ureterorenoscopy (URS) is a surgical procedure that may be more easily practiced on adult and adolescent patients in comparison to children of preschool age. It is more prone to complications in preschool children because the ureter is narrower and its perimeter is more delicate (7). This is why it is recommended to use semirigid ureteroscopes with smaller calibers in patients of this age group. This study aimed to assess the success of the semi-rigid (7-Fr) ureterorenoscope in treating ureteral stones in preschool children ( $0-6$ years of age).

\section{MATERIALS AND METHODS}

A total of 36 patients who underwent endoscopic ureteral stone treatment in the clinic between January 2012 and February 2018 were retrospectively evaluated. Routine urological physical examination, biochemical analysis, full urine test, and urinary culture procedures were carried out before the operation. The operation was performed after providing appropriate antibiotic therapy on patients with urinary infections whose urinary cultures were sterile. Direct urinary system graphy, urinary system graphy, intravenous pyelography, and/or noncontrast computerized tomography were used for stone localization. All patients were given 250 mg parenteral first-generation cephalosporin as a prophylactic before the operation.

In all patients, the URS procedure was carried out in the lithotomy position under general anesthesia. A 7-Fr semi-rigid ureterorenoscope (Karl Storz, 27000 L/K, Tuttlingen, Germany) was used for URS. The proximal diameter of this instrument was 7 $\mathrm{Fr}$, and its distal diameter was 6.5 Fr. A Holmium:YAG laser device (Dornier Medilas H30, Germany) used as lithotripter. During lithotripsy, 2 different probes with thicknesses of 400 and $600 \mu \mathrm{m}$ were preferred based on the size of the stone.

No routine ureteral dilatation was made. When ureteral entrance was difficult, access to the ureter was attempted using a 0.038inch hydrophilic guide wire (Sensor Guide Wire, Boston Scientific, USA). In cases where ureteral access could not be achieved or the stone could not be reached, 1 month of passive dilatation was performed by placing a double J (DJ) stent. The temporary ureteral stents were removed after 12-24 h, and the DJ stents were removed in the fourth week with short-term anesthesia.

The stone-free state of the patients was assessed visually during fragmentation using urinary ultrasonography after 1 month.

\section{RESULTS}

The demographic information on the patients, stones, and operations is shown in Table 1.

The mean age of the patients was 37.5 months (8-72); $55.6 \%$ of the patients (20/36) were male, while $44.4 \%(16 / 36)$ were female. Stone localization was $58.3 \%(21 / 36)$ in the distal ureter, $16.7 \%(6 / 36)$ in the middle ureter, and $25 \%(9 / 36)$ in the proximal ureter. The stones were found in the left and right ureters in 55.6\% (20/36) and 44.4\% (16/36) of the patients, respectively. The stone-free rate after the first ureterorenoscopy procedure was $58.3 \%(21 / 36)$. DJ stents were attached to the patients where intraoperative stones were not reached during the first ureterorenoscopy procedure $(38.9 \%, 14 / 36)$. The second-session ureterorenoscopy was applied after 1 month. Ureteral perforation occurred in $2.8 \%$ of the patients $(1 / 36)$ after the first ureterorenoscopy procedure. Ureterolithotomy was applied by open surgery. The stone-free rate after the first and second ureterorenoscopy procedures was $97.2 \%$ (35/36). After the operation, $72.2 \%$ of the patients $(n=26)$ received double J stents, and $16.7 \%(n=6)$ received ureteral catheters. No ureteral catheterization was carried out in $11.1 \%$ of the patients $(n=4)$. Mild hemorrhage was observed in two patients (5.5\%) and high fever $\left(>38.5^{\circ} \mathrm{C}\right)$ in four patients $(11.1 \%)$ In the early postoperative period. The mean duration of hospitalization was 2.3 days (1-7).

\section{DISCUSSION}

The prevalence of USSD in Turkey was reported as $11.1 \%$. This ratio was higher in the Southeastern Anatolia Region (8). Minimally invasive methods are prominent because USSD, which is observed in children, has a risk of recurring in further periods of life.

ESWL and URS are the two most frequently practiced methods for treating ureteral stones in children. High success rates are reported for both methods. While selecting between these two treatment methods, it is recommended to consider the experience of the urologist, the availability of the required equipment, and 
TABLE 1: Characteristics of patients, stones, and operations.

\begin{tabular}{|c|c|c|c|}
\hline & Frequency $(n)$ & $\%$ & Mean \\
\hline Age (month) & & & 37.5 \\
\hline Female/Male & $16 / 20$ & & \\
\hline Stone location (right/left) & $16 / 20$ & & \\
\hline History of failed ESWL & 6 & & \\
\hline \multicolumn{4}{|l|}{ Stone localization } \\
\hline Proximal ureter & 9 & 25 & \\
\hline Medial ureter & 6 & 16.7 & \\
\hline Distal ureter & 21 & 58.3 & \\
\hline Stone size $(\mathrm{mm})$ & & & 9.69 \\
\hline Stone-free after the first URS procedure & 21 & 58.3 & \\
\hline Stone-free after the first and second URS procedures & 35 & 97.2 & \\
\hline \multicolumn{4}{|l|}{ Complications } \\
\hline \multicolumn{4}{|l|}{ Intraoperative } \\
\hline Failure to reach the stone & 14 & 38.9 & \\
\hline Mild hemorrhage & 2 & 5.5 & \\
\hline Ureteral perforation & 1 & 2.8 & \\
\hline \multicolumn{4}{|l|}{ Postoperative } \\
\hline High fever $\left(>38.5^{\circ} \mathrm{C}\right)$ & 4 & 11.1 & \\
\hline Hospitalization time (day) & & & 2.3 \\
\hline
\end{tabular}

the preference of the patient (9). The low rates of success in ESWL, especially moving from the proximal ureter to lower levels, have made URS the first option for treating these stones $(10,11)$.

Considering its effectiveness and safety, URS is more preferred for treating pediatric ureteral stone disease using thinner-caliber ureterorenoscopes (12).

Recent studies showed that the effectiveness of URS had come close to $100 \%$ due to increased surgical experience, thinner equipment, and use of laser lithotripsy in clinical practice $(13,14)$. Atar et al. (15) reported that the effectiveness of URS carried out in children aged younger than 3 years using a 7.5- $\mathrm{Fr}$ ureterorenoscope was $66.7 \%$, while this rate increased to $93.5 \%$ when a 4.5-Fr ureterorenoscope was used.

The stone-free rate after the first URS procedure in the present study was $58.3 \%$. DJ stents were placed in patients where intraoperative stones could not be reached during the first URS procedure, and the second session of ureterorenoscopy was applied after 4 weeks. The stone-free rate after the first and second URS procedures was
97.2\%. Passing the ureteral orifice is one of the most important steps during URS. The use of a guide wire and/or hydro-dilatation techniques makes ureteral entry easier (16).

Although the widespread use of active or passive ureteral dilatation was preferred in the first years of URS, recent studies have shown that routine ureteral dilatation is not necessary $(15,17,18)$. Hence, routine ureteral dilatation was not conducted in the present study. During URS, another operation may be required if ureteral engagement cannot be achieved due to any reason and the stone cannot be accessed. Further, $4.5 \%$ of the cases in the study by Geçit et al. and $9.25 \%$ of those in the study by Yücel et al. required an additional URS treatment $(19,20)$. This rate was $38.9 \%$ in the present study.

Although URS is a minimally invasive intervention, it may lead to some complications $(21,22)$. Studies in the literature reported major complications such as ureteral perforation, obstruction, avulsion, and gross hematuria, and minor complications such as mucosal laceration, mild hematuria, stone migration, renal 
colic, and inflammatory urinary system infection (22). Ureteral perforation is a rare but important complication of URS. It usually occurs during uncontrolled pushing of the ureteroscope forward or during lithotripsy. Ureteral perforation rates have dropped to less than $2 \%$ using lower-caliber ureteroscopes in recent years $(22,23)$. In the case of perforation, the intervention should be stopped and the placement of a DJ stent should be considered as the first option for treatment (24). If a DJ stent cannot be placed, percutaneous nephrostomy insertion or open surgery may be carried out as the last alternative (25). In the present study, ureteral perforation occurred in only one (2.8\%) patient during the first URS procedure. Attempts were made to place a DJ stent as the first treatment option. When the DJ stent could not be placed, open surgery was started and ureterolithotomy was applied.

URS-related minor complication rates were reported as between $9.7 \%$ and $18.6 \%(12,15,18,20)$. Minor complications such as minimal hemorrhage and high fever $\left(>38.5^{\circ} \mathrm{C}\right)$ were observed in $16.6 \%$ of the cases in the present study. This rate was comparable to those reported in the literature.

Placement of a stent into the ureter after URS is a debatable issue (26). If the stones have not been appropriately broken, edema may develop in the ureteral tissue surrounding the stone due to both the URS intervention and lithotripsy. This situation may be severe, and serious colic attacks and hydronephrosis may occur in the early periods. This is why a temporary ureteral stent or a DJ stent may be used based on the judgment of the surgeon (27).

In the present study 26 of the patients (72.2\%) received DJ stents and $6(16.7 \%)$ received temporary ureteral catheters after URS. No ureteral catheterization was made in four (11.1\%) of the patients after URS.

Infection is the most frequently encountered complication in the early postoperative period [5], and the clinical picture may vary from mild fever to sepsis. The best way to prevent such complications is sterilizing the urine before the intervention. High fever $\left(>38.5^{\circ} \mathrm{C}\right)$ was observed in four patients in the present study (11.1\%) in the early postoperative period, and it was treated using the appropriate antibiotic therapy.

The limitations of the present study were that it was a retrospective study, and it did not include stone analysis or another group for comparison.

\section{CONCLUSIONS}

URS is an extremely effective treatment option for pediatric ureteral stones. The endoscopic ureteral stone treatment used for preschool children with a 7-Fr ureterorenoscope may be applied with high success rates and safety even in children of quite early ages.

\section{REFERENCES}

1. Schwarz RD, Dwyer NT. Pediatric kidney stones: Long-term outcomes. Urology 2006;67:812-16.

2. Sas DJ. An update on the changing epidemiology and metabolic risk factors in pediatric kidney stone disease. Clin J Am Soc Nephrol 2011;6:2062-68.

3. Baştuğ F, Gündüz, Tülpar $S$, Poyrazoğlu H, Düşünsel R. Urolithiasis in infants: evaluation of risk factors. World J Urol 2013;31:1117-22.

4. Öner A, Demircin G, İpekçioğlu $H$, Bülbül $M$, Ecin N. Etiological and clinical patterns of urolithiasis in Turkish children. Eur Urol 1997;31:453-58.

5. Tiryaki T, Azili MN, Özmert S. Ureteroscopy for treatment of ureteral stones in children: factors influencing the outcome. Urology 2013;81:1047-51.

6. Onal B, Citgez S, Tansu N, Emin G, Demirkesen O, Talat Z et al. What changed in the management of pediatric Stones after the introduction of minimally invasive procedures? A single-center experience over 24 years. J Pediatr Urol 2013;9(6):910-14.

7. De la Rosette J, Denstedt J, Geavlete P, Keeley F, Matsuda T, Pearle $M$ et al. The clinical research office of the endourological society ureteroscopy global study: indications, complications, and outcomes in 11,885 patients. J Endourol 2014;28:131-39.

8. Muslumanoglu AY, Binbay M, Yuruk E, Akman T, Tepeler A, Esen $T$ et al. Updated epidemiologic study of urolithiasis in Turkey. I: Changing characteristics of urolithiasis. Urol Res 2011;39:309-14.

9. Turk TM, Jenkins AD. A comparison of ureteroscopy to insitu extracorporeal shockwave lithotripsy for the treatment of distal ureteral calculi. J Urol 1999;161(1):45-7.

10. Kara C, Bayindir M, Çiçekbilek I, Oguz U, Ünsal A. Üreter alt uç taslarinin tedavisinde üreteroskopi ile vücut dısı sok dalga litotripsinin karsilastirilmasi. Turkish Journal of Urology 2009;35(1):28.

11. Puppo P, Ricciotti G, Bozzo W, Introini C. Primary endoscopic treatment of ureteric calculi. A review of 378 cases. Eur Urol 1999;36(1):48-52.

12. Utanğaç MM, Dağgülli $M$, Dede $O$, Sancaktutar AA, Bozkurt $Y$. Effectiveness of ureteroscopy among the youngest patients: One centre's experience in an endemic region in Turkey. Journal of Pediatric Urology 2017;13(1), 37-e1.

13. Thomas JC, De Marco RT, Donohoe JM, Adams MC, Brock JW, Pope JC. Pediatric ureteroscopic Stone management. J Urol 2005;174(3):1072-74.

14. Chow GK, Patterson DE, Blute ML, Segura JW. Ureteroscopy: effect of technology and technique on clinical practice. J Urol 2003;170(1):99-102.

15. Atar M, Sancaktutar AA, Penbegul N, Soylemez H, Bodakci MN, Hatipoglu NK, et al. Comparison of a $4.5 \mathrm{~F}$ semi-rigid ureteroscope with a $7.5 \mathrm{~F}$ rigid ureteroscope in the treatment of ureteral stones in preschool-age children. Urol Res 2012;40(6):733-38. 
16. Soygur T, Zumrutbas AE, Gulpinar O, Suer E, Arikan N. Hydrodilation of the ureteral orifice in children renders ureteroscopic access possible without any further active dilation. J Urol 2006;176(1):285-87.

17. Gedik A, Orgen S, Akay AF, Sahin H, Bircan MK. Semi-rigid ureterorenoscopy in children without ureteral dilatation. Int Urol Nephrol 2008;40(1):11-14.

18. Sancaktutar AA, Atar M, Söylemez H, Bozkurt $Y$, Penbegul $N$, Bodakcı MN et al. Effectiveness of $4.5 \mathrm{~F}$ semirigid ureteroscope (Mini-URS) in the management of ureteral stones in children younger than 3 years of age. Turk J Urol 2011;37(4):335-40.

19. Gecit I, Pirincci N, Günes M, Bilici S, Taken K, Göktas U et al. Should ureteroscopy be considered as the first choice for proximal ureter stones of children? Eur Rev Med Pharmacol Sci 2013;17(13):1839-44.

20. Yucel S, Akin Y, Kol A, Danisman A, Guntekin E. Experience on semirigid ureteroscopy and pneumatic lithotripsy in children at a single center. World J Urol 2011;29(26):719-23.

21. Dogan HS, Onal B, Satar N, Aygun C, Piskin M, Tanriverdi O et al. Factors affecting complication rates of ureteroscopic lithotripsy in children: results of multiinstitutional retrospective analysis by pediatric stone disease study group of Turkish Pediatric Urology Society. J Urol 2011;186(3):1035-40.
22. Fuganti $P E$, Pires $S$, Bronco $R$, Porto J. Predictive factors for intraoperative complications in semirigid ureteroscopy: analysis of 1235 ballistic ureterolithotripsies. Urology 2008;72(4):770-74.

23. Bader MJ, Eisner B, Porpiglia F, Preminger GM, Tiselius HG. Contemporary management of ureteral Stones. Eur Urol 2012;6:764-72.

24. Butler MR, Power RE, Thornhill JA, Ahmad I, McLornan I, McDermott T, et al. An audit of 2273 ureteroscopies e a focus on intra-operative complications to justify proactive management of ureteric calculi. Surgeon 2004;2(1):42-46.

25. Georgescu D, Mult,escu R, Geavlete B, Geavlete P. Intraoperative complications after 8150 semirigid ureteroscopies for ureteral lithiasis: risk analysis and management. Chirurgia 2014;109(3):36974.

26. Herndon CA, Viamonte L, Joseph DB. Ureteroscopy in children: is there a need for ureteral dilation and postoperative stenting? J Pediatr Urol 2006;2(4):290-93.

27. Galal EM, Fath El-Bab TK, Abdelhamid AM. Outcome of ureteroscopy for treatment of pediatric ureteral stones. J Pediatr Urol 2013;9(4):476-78. 